\title{
Factors Affecting Sustainability of Women Enterprises: Insights from Kapsabet Town (KT) Experience, Kenya
}

\author{
Susan Wanjiku Njogu \\ Institute of Women, Gender and Development Studies, Egerton University, Njoro, Kenya
}

\section{Email address:}

susannjogu66@yahoo.com

\section{To cite this article:}

Susan Wanjiku Njogu. Factors Affecting Sustainability of Women Enterprises: Insights from Kapsabet Town (KT) Experience, Kenya. Humanities and Social Sciences. Vol. 4, No. 4, 2016, pp. 90-99. doi: 10.11648/j.hss.20160404.12

Received: May 8, 2016; Accepted: May 25, 2016; Published: June 30, 2016

\begin{abstract}
The main purpose of this study was to investigate the factors affecting sustainability of women enterprises. The specific objectives of the study were: to determine the effects of the managerial skills on the sustainability of the women enterprises in Kapsabet town, to identify the effects of financial requirement on the sustainability of women enterprises in Kapsabet town, to analyse how legislative and legal requirement affect the sustainability of women enterprise in Kapsabet town, and to determine the cultural factors affecting sustainability of women enterprises in Kapsabet to town. It is hoped that the study results will be used by the Government through the Ministries of Youth Affairs (MOYA), Gender and social services in developing policies for the disbursement of the Youth and Women funds to the small businesses. A survey research design was adopted for the study. The target population under the study comprised 80 women owners of retail shops within Kapsabet town. Stratified sampling technique was used to select a sample of 40 respondents who represented the target population. Questionnaires were used as the data collection instruments. It contained closed end questions. Data analysis was done using descriptive statistics and presentation of the results was done in form of tables, graphs and charts. The findings revealed that, organization culture, availability of finance, legal requirements and managerial skills affect the sustainability of women enterprises in Kapasabet town. The researcher recommended that the owners of the women enterprise should possess good managerial skills, adhere to the governing laws and have good working culture to ensure the survival of their businesses. Researcher recommended a replication of the study be done in other areas to ensure generalization of findings.
\end{abstract}

Keywords: Sustainability, Women Enterprises, Kapsabet Town

\section{Introduction}

\subsection{Background of the Study}

Women enterprises are firms of business that are mostly owned and managed by the owners and have less than 50 employees. They are always at a very high risk of failure. They risks involved are sometimes high and in as much as returns may be high loses may be encountered in the event of failure (Gareth, 1998). The price is a value of a good or services by some customers at some point. For a product or services price has a very strong effect on performance for example by lowering the customers establishing a good relations as they will always continue stays a big role in offsetting a competitive trust because of its effects (Kibera and Waruinge, 1998)

The term (sustainability) is commonly expressed in association with finding funds for community based organization. The interpretation of its meaning does address the citizen's central concerns and values, looks to the future strengths a community ability to deal with the change develop processes for finding common ground, strives to benefit all members of a community, emphasizes citizen involvement, improves accountability develops a vision for further, keeps track of the progress and meets the basic resources needs (Thomas, 2001)

Sustainability may be defined as the ability of the system to perpetuate itself using locally approved strategies(mission) which are predetermined by the governance of the system who would like the system to continue until its goals (vision ) are fulfilled (Thomas, 2001). Sustainability of the vision and mission of the program refers to preserving, perpetuating, maintaining, keeping alive or keeping going in relation to the goals of the program. Although the term sustainability 
implies a continuation of a program in some way different emphasis of meaning have been noted (Rizkallah, 1998).

Overall experience of authors suggest the importance of planning for sustainability from inception of any initiative, strong planning cannot support sustainability factors across the area of program and implementation as well as contextual factors. As such evaluators may be able to play an important role in this process through a focus on clarification evaluation at early stages of program development to ensure on integration of this elements. Further, evaluators should support the use of regular monitoring and evaluation to identity and communicate success and important element in assisting the sustained use of any program (Owen 1999). The study was focused on the factors affecting sustainability of women enterprises in Kapsabet town. These factors are management skills, financial requirement culture and legislative and legal requirement. The women enterprise under the study was women enterprises based within Kapsabet town.

\subsection{Statement of the Problem}

The number of women owned businesses are increasing being promoted by both the government and private sector. They are highly supported and expected to perform well. Most microfinance institutions have been formed to champion for the success of women owned businesses. Despite all this, most of small scale businesses owned by women are not able to their 2 nd birthday. They close down or become stagnant and no evidence of growths. Very few women owned businesses have attained their desired levels of growth despite the major support they receive. There has not been systematic study undertaken to determine the challenges facing the sustainability of small scale enterprises specifically women owned enterprises. Therefore this study was aimed at establishing the challenges which are facing the sustainability of women enterprises in Kapsabet town.

\subsection{Objectives of the Study}

i. To determine the effects of the managerial skills on the sustainability of the women enterprises in Kapsabet town

ii. To identify the effects of financial requirement on the sustainability of women enterprises in Kapsabet town

iii. To establish how legal requirement affects the sustainability of women enterprise in Kapsabet town

iv. To establish the cultural factors affecting sustainability of women enterprises in Kapsabet to town

\subsection{Significance of the Study}

It is hoped that the study results will be used by the Government through the Ministries of Youth Affairs (MOYA), Gender and social services in developing policies for the disbursement of the Youth and Women funds to the small businesses. It can be one input to existing Women Entrepreneurs, potential entrepreneurs, MSE heads of the town and the region to alleviate the problems that women entrepreneurs face.

\section{Literature Review}

\subsection{Theoretical Review}

\subsubsection{Managerial Skills}

Kotter (2002) agreed that management skills are effective in achieving business goals by performing the major roles of planning for example; selecting objectives, missions and actions in achieving their decision making and forecasting future courses of action to achieve them. The management of a business usually affects or influences the sustainability performance and success of a business enterprise. In the opinion of creditors and others who have dealt with demised firms, management is viewed as the underlying cause, which is around $98 \%$ of the business facilities. Management is attributed to the owner's experience and unbalanced management training (Don and Bradstrust, 1984).

Professional training is also important in development, sustainability and growth of business enterprises. Both operators and managers should be skilled in the various areas of specialisation so as to enhance development, sustainability and performance of the business. For example; professionals like teachers, sales representatives, managers and secretaries should be well-trained in the various fields of specialization (McCormick, 1996).

Similar sentiments have been noted that for any enterprise to succeed it should have personnel with technical know-how on their relevant jobs so as to attract both potential and new customers so as to create new and sustain existing markets for their products or services. This implies that technical skills in one's area of specialisation is important for the growth of business enterprise and also emphasizes on the centrality of professional skills in the operation and management of business enterprise.

Development Plan (1997) effective training increases morale most of these small businesses start and remain small because the income generated from the sale of goods and services offered are used to meet their personal needs, therefore due to lack of management skills and experience, records are not properly kept. Kotler (2002) agrees that management skills are being effective in achieving organisation's goals by performing the major functions of management planning, controlling, staffing and organising. Today, continuing management education and training are integral steps in building management skills because new theories and techniques are constantly being promoted to improve organisation effectiveness. A quick scan, although managers (Business week for fortunes) reveals a trust of seminars in topics such as finance leadership, managing human resources, advanced marketing and the global business environment are being offered to managers at many levels of organisation and to most senior corporate executives to middle managers.

Small business enterprises (SBE's) should have some knowledge on how to run the business as this will help them know how to operate their enterprises. Lack of these skills may lead to lack of achieving business goals and they can end up not estimating the actual figure which will lead to an 
enterprise to run at a loss. A good manager or a good entrepreneur of a business will make quite faster and quality decisions that are innovative and move the business to the next level. Any delay in decision making means lost opportunity.

Beardwell and Holden (1997) recognised that training ia a planned process to modify attitude; knowledge, skills or behaviour through learning experience to achieve effective performance. The purpose is to develop an individual's ability to satisfy current and future needs of their businesses. This enables the individuals to perform their job effectively, take in new responsibility and adapt to changing market conditions.

Management influences growth and sustainability of SSEs. Management is cited as the underlying cause which is around $98 \%$ of business facilities. Further management is attributed to the owners' experience and unbalanced management training. Similarly management leads to mistake in strategic planning and implementation. This may result to deterioration in growth indicators and therefore without any corrective action the business may end up falling. This implies that managerial skills are vital if effective growth is to be attained in the small scale sector. The above studies are relevant to the current study because they indicate that the way small enterprises are managed will influence their sustainability (Sharn and Mahajan, 1980).

Management skills are required to give the desired performance level in a given area. The skills are important as they help managers to avoid neglecting basic policy making as they get bagged down in recurring operating problems. Due to the fluctuations in market performance, management skills are important to managers to learn how to set attainable goals and also be able to acquire information of the customer needs and performance of the competitors

According to Nyakerano (2004) in her study on factors affecting the growth of small scale enterprises she identified that professional training is equally important to the growth and development of business enterprises. For any business to succeed, it should have personnel with technical know-how in relevant jobs so as to attract new customers in order to create market for their products and services. She also asserts that for an enterprise to grow sufficient and proper accounting systems and procedure should be put in place. Most of these small scale businesses start and remain small because the income generated from the sales of goods and services offered are used to meet their personal needs. Therefore due to lack of managerial skills and experience records are not properly kept.

Beardwell and Holden (1997) recognise training as a planned process to modify attitude, knowledge and skill behaviour through learning experience to achieve effective or improved performance. The purpose of management skills is to develop the ability of an individual to satisfy current and future needs of the business. Training ensures managers of SSEs have the knowledge and skills needed to perform their jobs effectively, take on new responsibilities and adopt to changing conditions (Dilworth, 1993).
Zikmond et al 1995 outlined that small scale owners must manage all aspects of these businesses. They offer lack experience or expertise in many activities involved in running the business. Learning by trial and error is possible but often necessarily experience comes too late and business falls. Even when a business succeeds, the small business owner must make up for lack of experience with long hours. Under- estimating the strength of existing competition is a mistake often made by overly optimistic small business managers. Such managers fail to anticipate future competitive reactions. All often, the enthusiastic small business manager finds that it takes more time and effort than expected to successfully start up a business.

Besides, professional managerial training is equally important to the development and growth of business enterprises. Operators should be skilled in various areas of specialisation for example accountants should be skilled in various areas of specialisation for example accountants, chefs, cooks, waiters and managers should be trained in their various fields of specialisation (McCormick, 1996).

Similar sentiments have been advocated by Gichira and Dickson (1996) who indicated that for any enterprise to succeed it should have personnel with technical know-how in relevant jobs so as to attract both potential and new customers in order to create market for their products and services. This implies that technical skills in one's area of specialisation is important for the growth of a small scale enterprise and hence sustainability in the competitive market. The above studies are relevant to the current study because they put emphasis on centrality of professional skills in the operation and management of small scale enterprises. However they tend to generalise on all activities in their sector without being specific.

In addition to having a knowledge base, management skills are required to give desired performance level in a given area. Technical skills reflect understanding and proficiency in specialised fields. Human skills help managers to get ability to work well with others both as members of a group and as leader who gets things done through others. Conceptual skills are related to the ability which visualise an organisation as a whole, discern inter-relationship among organisational parts and understand how the organisation lists the wider context of the industry, community and the world (Gareth et al., 1998).

Management skills are important as they help managers to avoid neglecting basic policy making as they get bogged down in recurring problems. There is the need for training manager since they are sales managers, pricing exports and advertising managers. Management skills help entrepreneurs to do feasibility studies of total cost of investment and avoid under-estimating the necessary cost (Ibid).

\subsubsection{Constraints to Financial Requirements}

Access to finance and credit facilities have remained dominant constraints to sustainability of women's enterprises. Parkers and Bain (1990) found out that most of the respondents faced credit constraints pertaining to working capital and other inputs. 
Finance is an important factor in the sustainability of small business enterprises. Olysyniski (2000) points out that money is the main reason why people will go to business for themselves and the business offers possibility of generating attractive enterprises. Many micro-enterprises fall because their owner thinks that when a product is so good it will sell itself and fail to provide adequate funds to operate the business. No matter how much efforts put into the business without capital, it will fail.

Seibel (1998) argues that financial institutions operate under profit and legal constraints that make them reluctant to offer financial services to micro-enterprises. Kibuka (1998) agrees with Seibel's assertion by stating that difficulties in obtaining credit facilities hinder growth of many women enterprises due to the fact that investors often require raising some capital through borrowing. Therefore there is a need for financial institutions to lend a hand to businesses by relaxing some of their tough measures required for one to be able to obtain credits.

Kibuka (1992) explains constraints to credit faced by small scale enterprises. Among them include; lack of experience of borrowers with credit institutions, reluctance of formal financial institutions to lend money to women enterprises. Stringent collateral recruitment and high administrative overheads are also relative to the size of the loan. The credit worthiness of a business is one of the most valuable assets. Funds are needed for investing in assets and expanding the business in terms of increasing stocks and debtors.

\subsubsection{Legal and Legislative Requirements}

The laws of Kenya require every business to have a license in order to operate. The licence cost is currently at Kshs. 5,650 and keeps on increasing offer every two years. This acts as a challenge to some business owners who may not afford it. On the other hand the compulsory use of Kenyan Bureau of Standards (KEBS) mark on all consumers' against buying fake and harmful products from unscrupulous business people. Therefore it is important for businesses to comply with these rules in order to safeguard their interests.

According to Simiyu (2003) licences take form of single business permit and were passed in finance Bill of 1998, but became effective in the year 2000. Local authorities choose their own schedules as it is single permit fee structure. The different authorities include county councils, municipal councils and city councils for the large cities. Each local authority is legally an independent entity. The corporate body is popularly elected and has power over local taxations. This licensing therefore affects the small and large firms as they are forced to adhere to the local authorities' requirements in order to operate. Taxes and licences' fee affect the price products and items to the same extent. Kapsabet town council license late payments attract a penalty of 3\% per month.

According to Jepkorir (2007) many government regulations made with the good intentions actively discourage and restricts small scale development. The licensing procedures import quotas and tax exemption privileges encourage large firms at the expense of small businesses. The governments get into a difficult position since it has to protect public interest but at the same time avoid measures that strife developments of sectors which employ so many people. This small business sector ends up in corruption with council officers for non-adherence of trade licences.

\subsubsection{Cultural Factors}

Culture is a pattern of norms, beliefs, attitude and assumption that may not have been articulated but shape the ways in which people behave and things get done. Values refer to what is believed to be important about how people and the organisation behave. Norms are the unwritten rule of behaviour. They may not be defined, discussed or even Noticed, but another way, culture can be regarded as a code word for the subjective side (Mayerson and Martin, 1987).

Many cultures in Kenya have crippled the women by not allowing them to own property. This makes it difficult for a woman to own lands as well as other valuable property. Men culturally take all the credit of being the head of the family and therefore all properties belong to them. One of the KWFT requirements for acquiring a biashara loan is that the group members are expected to agree to co-guarantee each other and pledge household assets. How will the woman who is denied the change acquire the loan if she succeeds? How does she repay it? (Alela, 2002)

The Kenyan society is predominantly patriarchal patrilineal and patri-local. Three fundamental features characterising patriarchy are the patrilineal inheritance system control over women's sexuality and bodies and restrictions over women's mobility. Women are given a subordinate position at all levels, economic control and power over body and movement and power of family lineage that at the most intrinsically basic level, women are reduced to a position of secondary importance. All forms of discrimination and inequality ensue from this. Therefore patriarchy operationalized through the family system needs to be carefully analysed. (Odongo, 1998)

Ceda (1981) suggests that the gender division of labour leading to gender stereotyping of jobs in traditional frature of Kenyan society. Women working hours tend to be very long and strenuous in rural setting. Household chores such as cooking and washing, fetching water and firewood combined with agriculture related activities engage them for more than ten - twelve hours. In an urban setting, most working women face double responsibilities of household work as well as the professional demands of their jobs.

A high level of stress and irritation has been expressed by many of these women who end up trying to be super-women trying to cope with and even excel in both the inside and outside worlds often leads to psychological trauma. The status of women showed a strong relationship between women's level of input in the outside economy and decision making process within the households.

The recent updated study by Shrii Shakti (1995) revealed that a surprising downward trend in decision making for women despite a total improvement in the household. Income 
as a result of development intervention, personal decision making for women has decreased considerably. It may be the choice and decision made by men thus making them more aware of their lower decision making power.

\subsubsection{Economic Stability}

Economy is judged against a backed representative of the economic indicator such as prices. Employment money supply stocks and return on capital, savings, interest rates, balance of payments, output and exchange rates. Any changes for example increase in inflation rate of a country, leads to increased prices for commodities. Therefore, this reduces the consumers' buying power. On the other hand, an increase in the level of employment increases consumer buying power due to increased.

The Sunday Standard (2005) describes Kenya in 1963 as being one of the most prosperous and politically stable countries in East Africa. However, the following two decades of economic down turn reversed this enviable position to a state of extensive poverty (currently estimated at $56 \%$ of the population) and economic decline GDP growth fall from approximately $7 \%$ in the 1970 s to just over $2 \%$ in the 1990 s. The resultant stagnation was accompanied by a decline in the efficiency of capital and factor productivity, hence negative impacting Kenya's competitiveness in the world economy.

McCormick (1996) observed that markets in developing countries are often small because of low purchasing power. The average population in the developing countries lives below the poverty line. They find it difficult to make ends meet because of an employment which directly and indirectly affects demand. Therefore a vision of the market opportunities is the key to a fast growing firm. However the above studies focussed on small scale sector in general while the current study focused on women enterprise in urban areas.

The new government elected on December 2002 stated that it is committed to reversing the past decade's economic decline, mismanagement, contraction in per capita income and decrease in number of people living below the poverty line. It had prepared the economic recovery strategy for wealth and employment creation 2003 - 2007 whose outlines are recovery central on a reanimated private sector. Reviving private sector activity and investment specifically micro small and medium-sized developments featured prominently in the government's strategy for raising incomes and employment. Although the economy of Kenya is said to have been growing considerably, there is much more needed to be done in order to improve the living standards of the people of Kenya and to develop the country as a whole.

Kotler (1996) states that markets require buying power as well as people. The economic environment of a particular country is evitable. It reflects the policies as adopted by successive governments and more recently, the impact of wider global trends. Literally, hundreds of variables can be used to monitor trends. However the key factors that concern marketers' mostly include the wealth of the country, interest rates as well as inflation rates. The wealth of a country is usually expressed in terms of Gross National Product (GNP).
This is the total market of all goods and services produced within an economy together with the country's overall earning for a given year (GNP). Figures provide a general indication of the economic wealth of a country.

Businesses are faced with various economic challenges. The dilemma presented to many in the service sector is framed in the lack of hard assets collateral to pledge for borrowing to fund both business purchase and business growth. The validation that sufficient hard set value exists to cover most of the remaining loan balance in the event of failure must also be provided. The ventures capitalist traditionally are not interested in small service business ventures and private money is normally just too expensive for the enterprise to survive this type of debt load (Wilbur 2000).

Studies by Marns et al (2000) on African businessmen, shows that there is need for finding small scale businesses through loans. In Kenya, Uganda and United States, whenever the promotion of small scale business has become an aim of policy, loans have been the first and the most important inducement. But there are inherent difficulties in any public loan scheme designed to out flaw the caution of private financing.

Perce et al. (2003) on strategic management show that economic factors or economic stability concern the nature and direction of economy in which the firms operate. Because assumption patterns are affected by relative affluence of various market segments each firm or enterprise must consider economic trends in the segment that affects industry.

Consequently the purchase of very expensive imports is relatively low to the population size. Two economic factors reflect the country's attractiveness as a market. The country industrial structure shapes its products and service needs, income levels and employment levels. The four types of industrial structure include: subsistence raw materials, exporting economies, industrializing and industrial economies, and countries with subsistence economies may consist mostly of household items with very low family income. These small and medium enterprises face many challenges in understanding how the economic environment will affect decisions in the market.

Peter (2000) suggested that the government can and should provide a favourable economic and regulatory environment where small businesses can thrive. Macro- policies that favour overall economic growth, political and social policies that enhance stability and a developed industrial policy that encourages establishment of businesses of all sizes can be put in place by the government

\subsubsection{Availability of Markets}

Market is a key activity of any business. A business only grows if it is making sales. Markets exert a very strong influence and importance in any business in that the available resources of funds are maximally and efficiently used. Availability of a ready market translates into sales and hence profits for the business. Small scale enterprises will only grow or expand steadily if they are able to sell their stocks 
and bring new ones. A ready market ensures that enterprise is able to generate money and enhance continuity.

Saxena (2006) defined marketing as "understanding and responding to customer needs." Therefore, when developing a marketing campaign, a business owner should keep in mind a clear concept of women enterprises and its potential market. In order to know potential market needs and wants, the owner should carry out market research, come up with suitable, affordable and available products to potential customers.

To be successful in small scale enterprises, entrepreneurs need products and services customers want, have to listen to their customers' likes and dislikes then change the product and services to satisfy the new needs. Market research needs to be done to get more effective marketing decisions and also providing them with information before deciding what prices to charge their customers. They need to lower their prices to attract customers to buy and be high enough to give the business profit (Ibid).

An effective marketing programme blends all the marketing elements into a co- ordinated program designed to achieve the company's marketing objectives by delivering value to customers. The marketing mix constitutes the company's tactical tool for establishing a strong position in a target market, Kotler et al. (2002).

\subsubsection{Location of Business}

Location is one factor that must be considered by business dealers because of its availability to attract customers. The location of a business is a very important issue since it determines whether a business will be able to attract its target customers and get its market share particularly in a competitive environment. One major factor which affects location of the business is the area where the building to be rented is located (Kotler, 2001)

This is because the construction of their own or finding the best area to construct building may be a problem. This has led to some entrepreneurs operating their businesses in fixed premises while other small scale retailers are operating without fixed premises. Another factor which affects location of the business is the rising insecurity in the area which is brought about by unemployment. Small scale retail shops which have the best location and with fixed premises e.g. roadside traders, single shops and tied shops have an advantage over those retailers without fixed premises.

Therefore small scale businesses would be located where they will find ready markets where government regulation does not inhibit their location, where cheap labour is available and where there are effective and efficient transport and communication facilities. These small scale retail owners should therefore ensure that they locate their businesses where there are good transport and communication facilities. This will reduce the cost of selling or buying what is not the customer's choice. Therefore the transport systems and communication channels play a vital role in the success of every business (Nyakerano, 2004).

The location of a product or service in the market should be determined by the entrepreneurs. Location analyses include careful evaluation of the market factors such as; competitors, population growth, economic trends, highway developments and demographic or social economic patterns of consumers. Serving the market from good location can make the difference in the business success. The problem of how many facilities to have and where they should be located is accounted by the service and product.

Location analysis includes careful evaluation of market factors such as competitors' strength and location population growth, economic trends, high way developments and demographic or social economic patterns of the consumers. Serving the market from good locations can make the difference in a business success. According to Chase and Aquilano (1996) the problem of faculty location is common to new and existing businesses. Retailers must choose their location carefully for two reasons; first, location is typically the most important consideration in customers' store choice. What retail shop do you shop at? Usually, it is the shop closest to where one lives or works.

Second location decision is important because retailers can use them to develop sustainable competitive advantage. Retailers can change their pricing, service and merchandise assortments quickly. However location decisions are harder to change because retailers frequently have to make substantial investment to buy and develop real estate or commit to long term lease with developers. Thus retailers with excellent locations have a strategic advantage which competitors cannot easily copy.

For many organisations, location planning must emphasize customer behaviour and proximity to customers. If primary product is a service to the public, the consumer convenience may be the prime consideration. Location conveniences itself is often considered to be the service. Location decision may be regarded as responsibility of marketing staff instead of production or operations staff especially as it affects revenue rather than cost (Chase and Aquilano, 1996).

Location decision has become even more important in recent years. First there are more retailers opening a new location. This makes the better location even scarcer. A retailer may find a suitable location but high rent, long leases and expensive decorating can make it to be very costly.

Location can also influence morale, employee relations and public relations (Dilworth, 1993). He also describes the failure to make good decisions on locations creating expensive and long lasting consequences. Decisions to purchase land and construct a building involves significant amount of money; Mistake may literally set in concrete. Time and Effort spent in doing something wrong then correcting it will never be received. Perhaps even more expensive, it is less obvious and the cost of making a poor location decision and not correcting it

\subsubsection{Competition}

Kotler (2003) defined competition in the marketing approach as a business that satisfies the same customers' needs. Large scale firms have posed competition to small 
trade enterprises. This implies that entrepreneurs should be careful in differentiating their products and services to maintain and capture the market share. The businesses need to look at their entire dimension that identifies strategic groups within the industry.

Kotler and Armstrong (2004) also define competitors as other companies offering products and services to the same customers at the similar price. The key to winning customers and maintaining them by understands their needs and buying behaviour better than the competitors do and deliver products/services which are of good quality and more value. Micro-enterprises can develop strategies that give better rate of return than large firms. They should specialise in serving markets niche that major competitors overlook or ignore

Kotler (2002) agrees that for an organisation to be successful, it should do a better job than its competitors. Marketing strategies must be geared to the needs of consumers and also to the strategies of competitors' analysis. Designing organisation's marketing strategies begins with the competitor's analysis. The organisation constantly compares the value and customer satisfaction delivered by the product prices, channels and promotions. Lack of cohesiveness and wide range of small business enterprises (SBEs) limits their capacity to defend their collective interest and effectiveness.

Competitiveness is also about winning. Competitors are defined as companies trying to satisfy the same customers' needs or the same customer's group. The presence of competitors in a market will always affect the market performance of a company (Kotler and Armstrong, 1998).

\subsubsection{Security Constraints}

Although wide ranging structural reforms have been instituted by the government to ensure success for all entrepreneurs' prospects for enterprises still remain to be addressed at firm level. Many SSEs operate in unsecure environments characterised with robbery with violence, burglary, theft, fire among others. Many entrepreneurs are not aware of services provided by insurance firms to insure their businesses against risks. This makes it difficult to recover from any loss that can occur to them (Steel and Webster, 1990).

\subsection{Empirical Review}

According to Wachira and Kamau (1987) in their study they found out that the majority of entrepreneurs had little understanding of marketing principle. They had problems relating to promotion, advertising and no primary policy. Jelangat (2007) in her study on factors affecting the performance of small business enterprises found that it is important for entrepreneurs to consider favourable finance option to find their expansion and operations. They should be careful in differentiating their goods and services to that of the competitors, to maintain and capture the market share, acquire marketing skills, comply with government legal requirements and policies and locate their businesses in strategic places where target customers are within reach as well as there are other businesses selling the same goods and services.
Kerry (2006) on factors influencing the growth of small business enterprises suggest that organisation or women enterprises should try as much as possible to control internal environment which consists of customers, suppliers, competitors and the public on the other hand. It should implement the right strategies to deal with the external environment that is demographic, technological, cultural and political as well as legal favourable returns to the organisation.

Cole (2004) on his research on factors affecting the small business enterprises observed that due to lack of quality cycles employees feel that they have been left out in decision making. He noted that employees' participation should be considered as they help the organisation to have more and a wide range of solutions that threaten the success of the business.

Kagoru (1996) noted that poor management leads to mistakes in strategic planning and implementation so as to be evaluated and if proceeds for evaluation show that particular plan which was used is not successful and it should be replaced with other plans. Similarly, Musonza (2005) in her study on small scale business enterprises found out that the ever changing technological environment has led to low growth in the firms hence entrepreneurs keep on sniffing from one business to another. Similarly, another aspect that affects the sustainability of small business enterprises is the capital required to start or expand the business. On the whole, banks seems to favour large businesses other than the small businesses once it comes to disbursement of loans since they believe that large businesses have the necessary security.

Nyambwa (2003) on the analysis of the problems facing small business entrepreneurship found out that most of the small business enterprises was that people lacked management experience and do not know how to adequately manage their businesses. Therefore, they rely on their own intuitions rather than business principles for marketing decisions hence the overall low growth in their business.

A study by Harper (1992) recognises small businesses as the most promising means for the production and distribution of appropriate technologies. He highlights that every individual in the government and in particularly those responsible for employment and small enterprise promotion should or must be persuaded to appreciate the economic significant of the smallest enterprise.

A study by Mohammed (1989), on the informal sector in Kenya highlights that the informal sector in Kenya describes the customers as being the vital substances in the survival of the most businesses. Therefore it is important for the business owners to correctly identify customers and promote products or services that respond to customers' needs. According to Donald, Scorbuck, Nathan and Donut (1995), they argue that several models for site allocation have also been formulated and retailers assess a particular store's sales effectiveness by looking at the four indicators which are: Number of people passing by on an average day; percentage that enters the store and buying; and the average amount spent per sale.

Kemboi (2007) in her study on competition describes that 
business dealers should know their competitors' objectives, priorities, strengths and weaknesses and how they can react to these different competitive strategies. Understanding consumer influencing behaviour will keep a marketer to predict how consumers will respond to marketing strategies. Waihanya (2006) on her research on the role played by Kenya Industrial Estates (K. I. E.) in the growth of small businesses suggest that government should provide favourable economic and regulatory environment where small businesses can thrive.

Ngumo (1995) in the enterprise development journal argues that entrepreneurs learn by doing, seeing and being exposed to the best practice approaches. An article on failure of small businesses found out that only a third of reasons were external and majorities were internal due to lack of management expertise. This implies that professional training is equally important to the sustainability and growth of business enterprises.

Kipkemboi (2005) in his research on factors hindering establishment of boutique businesses says that legal aspects (licensing) limits many people from the business. This is due to the large amounts of money required for one to acquire the license. According to National Trade Policy (2007) revealed that small scale enterprises are seen in the number of people employed. Over half of private work force in Kenya is employed by small scale enterprises. In fact small scale enterprises have created more net jobs in recent years than the large scale enterprises have. The case is that over half of the national payroll is now provided by small scale enterprises.

National Trade Policy (2007) also revealed that 98\% of the businesses in the country are technically considered small. Although each micro-enterprise produces relatively few goods or services when all micro-enterprises are together the economic impact is substantial. According to the Daily Nation of Tuesday 11th September 2007 on Standardisation for micro-enterprises, statistics indicates that more than $95 \%$ of the world's businesses are small medium-sized. KEBS also states that for any business to grow, its vision should look beyond national boundaries by embracing international standards such as information and communication standardisation which allows micro - enterprises to reach far beyond their physical location in search for new markets.

Wandugi (1998) observed that once a business is established, expansion is compromised by lack of funds and credit borrowing usually provide start-up capital. Bank credit is simply not available for small scale operators because they usually do not have security and the administration's cost of micro-enterprises is prohibitive.

According to Shonko (2006) most micro-enterprises are faced with various challenges such as economic, technological and political environment surrounding them and they have made these micro-enterprises to have difficulties in growing. Though the small businesses are increasing daily, analysts argue that the sector is undergoing an irreversible change, a change that brings in both opportunities. This in turn has adversely affected the performance of micro-enterprises with revenue decreasing.
Pauline (2003) stated that product quality plays a major role in the product preference and purchase behaviour. Product quality is extremely important for image building in the current market situations especially to meet market conditions such as stiff competition, market policies and time period since the product was launched.

\subsection{Conceptual Framework}

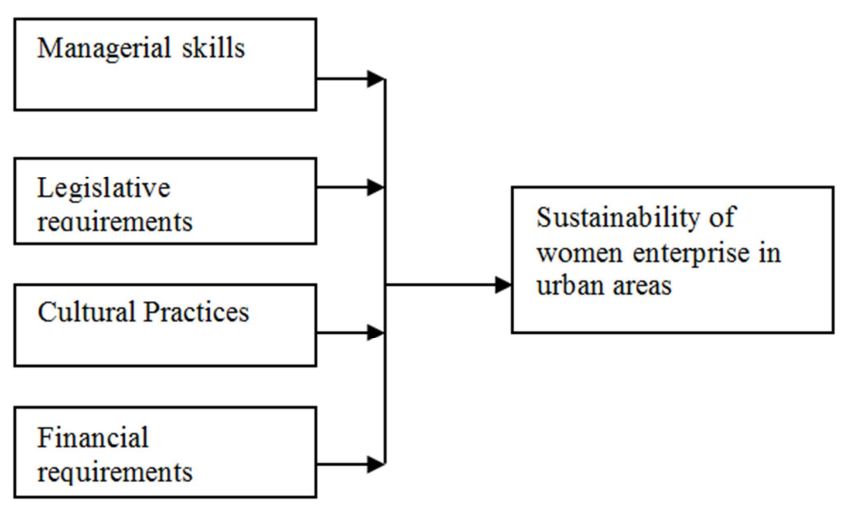

Figure 1. Conceptual Framework.

\section{Methodology}

\subsection{Research Design}

The study adopted a survey research design. A survey research design is the arrangement of conditions for collection and analysis of data in a manner that aims to combine relevance to research purpose with economy in procedure. It is the conceptual structure with which research is conducted. This design was appropriate for the study because it allowed collection of information generated from a sample to represent the overall target population. This design was judge as the most suitable method to answer the research questions. Through survey research design the researcher sought to gather information on factors affecting sustainability of women enterprises in Kapsabet town.

\subsection{Target Population}

The target population under the study comprised all women owners of retail shops within Kapsabet town. There are 80 retail shops in Kapsabet town. The number was arrived at counting women owned retail shops within the town. The women owned retail shops formed a target population of the study. The representation of the target population is represented in the table 1 .

Table 1. Target population.

\begin{tabular}{ll}
\hline Enterprises & Target population \\
\hline Kiosks & 19 \\
Shops & 11 \\
Vegetables groceries & 9 \\
hardware's & 18 \\
Hotels & 23 \\
Total & 80 \\
\hline
\end{tabular}

Source: KTC (2013) 


\subsection{Sampling Design and Procedures}

Stratified sampling technique was used to select a sample of 40 respondents who represented the target population. Proportionate sampling technique is approaches that divide the total population in to two or more groups called strata. In this case every individual within the target population had an equal chance of being selected. A sample refers to a group of individual or elements drawn from a large group called population while sampling procedures reverse to method used to draw the representative sample. The sample size of each stratum was arrived at by dividing the population and multiplying the answer with the total sample.

Table 2. Sample Size.

\begin{tabular}{lll}
\hline Departments & Target population & Sample size \\
\hline Kiosks & 19 & 10 \\
Shops & 11 & 5 \\
Vegetable groceries & 9 & 4 \\
hardware's & 18 & 9 \\
Hotels & 23 & 12 \\
Total & 80 & 40 \\
\hline
\end{tabular}

\subsection{Data Collection Instruments and Procedures}

The main data collection instrument used was closed ended questionnaire. The researcher administered the questionnaires on a drop and pick later basis to allow the respondents an ample time to fill in the questionnaires. The researcher also availed herself to offer assistance where necessary. To ensure that the instrument was valid and reliable, the researcher ensured that there is clarity and no errors were detected. This was achieved by the assistance of research supervisor who analyzed and ratified that the questionnaire covered all the objectives. To test the reliability of the instrument the researcher did a pretest at Nakuru town, where 10 questionnaires were issued to women enterprises in the town and instrument was found to be valid and reliable. Therefore it was adopted for the study.

\subsection{Data Analysis and Presentation}

Data collected from the field was edited and coded for completeness after which it was summarized and analyzed using descriptive statistics such as frequencies and percentages. Presentation of the results was done in the form of tables, charts, and graphs which facilitated clear interpretation of results and drawing of conclusions.

\section{Results}

\subsection{Managerial Skills and Sustainability of Women Enterprise in Urban Areas}

From table 3, the study revealed that the relationship between Managerial skills and Sustainability of women enterprise in urban areas was positive, strong and statistically significant $(r=0.536 ; p<0.05)$. It is therefore evident that managerial skills are a determinant of Sustainability of women enterprise in urban areas. It is very hard to run a business with any formal of training, a person operating the business should have managerial skills this will help him or her to run the business without difficulties.

Table 3. Correlation between Managerial skills and Sustainability of women enterprise in6 urban areas.

\begin{tabular}{lll}
\hline & & Sustainability \\
\hline \multirow{3}{*}{ Managerial Skills } & Pearson Correlation & $.536^{* *}$ \\
& Sig. (2-tailed) & .038 \\
& $\mathrm{~N}$ & 40 \\
\hline
\end{tabular}

**. Correlation is significant at the 0.05 level (1-tailed).

\subsection{Legislative Requirements and Sustainability of Women Enterprise in Urban Areas}

Table 4. Correlation between Legislative Requirements and Sustainability of women enterprise in urban areas.

\begin{tabular}{lll}
\hline & & Sustainability \\
\hline \multirow{2}{*}{ Legislative Requirements } & Pearson Correlation & $416^{* *}$ \\
& Sig. (2-tailed) & .045 \\
& $\mathrm{~N}$ & 40 \\
\hline
\end{tabular}

**. Correlation is significant at the 0.05 level (1-tailed).

The study revealed that the relationship between Legislative Requirements and Sustainability of women enterprise in urban areas was positive, relatively weak and statistically significant $(\mathrm{r}=0.416 ; \mathrm{p}<0.05)$. This implies that Legislative Requirements are determinants of Sustainability of women enterprise in urban areas. Government involvement in empowering women can greatly lift the women from their status in the society and they will start empowering themselves by participating in business and leadership.

\subsection{Cultural Practices and Sustainability of Women Enterprise in Urban Areas}

Table 5. Correlation between Cultural Practices and Sustainability of women enterprise in urban areas.

\begin{tabular}{lll}
\hline & & Sustainability \\
\hline \multirow{3}{*}{ Cultural Practices } & Pearson Correlation & $.554^{* *}$ \\
& Sig. (2-tailed) & .036 \\
& $\mathrm{~N}$ & 40 \\
\hline
\end{tabular}

**. Correlation is significant at the 0.05 level (1-tailed).

The study indicated that the relationship between Cultural Practices and Sustainability of women enterprise in urban areas was positive and statistically significant $(\mathrm{r}=0.554$; $\mathrm{p}<$ 0.01 ). This implies that cultural practices are critical factors in sustainability of women enterprise in urban areas. Culture is a crucial factor which is limiting the women form participating in business field, culture norms is the most factor which is making not to participate in any business it's like a boundary separating women with business. 


\subsection{Financial Requirements and Sustainability of Women Enterprise in Urban Areas}

Table 6. Correlations between Financial Requirements and Sustainability of women enterprise in urban areas.

\begin{tabular}{lll}
\hline & & Sustainability \\
\hline \multirow{2}{*}{ Financial } & Pearson Correlation & $.524^{* *}$ \\
Requirements & Sig. (2-tailed) & .016 \\
& $\mathrm{~N}$ & 40 \\
\hline
\end{tabular}

**. Correlation is significant at the 0.05 level (1-tailed).

From table 6 , the study revealed that the relationship between Financial Requirements and Sustainability of women enterprise in urban areas was positive, strong and statistically significant $(\mathrm{r}=0.526 ; \mathrm{p}<0.16)$. It is therefore clear that financial requirements are a determinant of Sustainability of women enterprise in urban areas. Through favorable credit policies from institution issuing loans to women, now women are able to get source of finance to start business either large scale or small scale

\subsection{Conclusions and Recommendations}

The purpose of the study was to investigate the factors affecting sustainability of Women Enterprises in urban areas. The study concluded that Managerial skills, Legislative Requirements, Cultural Practices and Financial Requirements are all critical determinants of Sustainability of women enterprise in urban areas.

Based on the research findings, the researcher recommended that the women enterprises should increase their training program within and without the organizations in order to enhance the competence of their employees. This will go a long way in improving the performance hence leading to sustainability of the enterprises. The researcher further recommended that there is need for the women enterprises to look for a good financial source that will support them in case of financial shortage in the organization thus will help in sustaining them for long in the business. The researcher also recommended that the organizations should abide by the regulations and laws set by the government to regulate enterprises in order to avoid confiscation and closure by the government. Lastly, the researcher recommended that the women enterprises should adopt good organization culture that will allow for smooth running of the business thus enabling sustainability.

\section{References}

[1] Adaya, S. (2000). Exploring Entrepreneurship in a Declining Economy, Journal of Developmental Entrepreneurship, 5(1), 41-47.
[2] Admassie, A. \& Amha, W. (2008). Public Private Partnership Projects of the GTZ in Ethiopia: International Trade and the protection of Natural resources in Ethiopia.

[3] Agumbi, R. and Odhiambo J. (2000). An Evaluation of Financial Self - Sustainability of MFIs in Kenya. Unpublished Master's Thesis, Jomo Kenyatta University of Agriculture and Technology.

[4] Aleke -Dondo, C. (1989). Assisting the informal sector comparing methodologies and performance, Kenya Rural Enterprise Programme, Sessional, Nairobi (1995).

[5] Alila, P. O. (1988). Rural Development in Kenya: A Review of Past Experiences. Regional Development Dialogue. Vol. No. 2. Summer.

[6] Alila, P. O. and Obado, P. O. (1990). Co-operative Credit: The Kenyan SACCOs in a Historical Perspective. Working Paper No. 474, Institute of Development Studies, University of Nairobi, Kenya.

[7] Birley, S. J., (1987). Britain's new enterprise programmes. Journal of Small Business Management, 23(4), 6-12.

[8] Bonn: Eschoborn. APEC (1994). "The APEC Survey on Small and Medium Enterprises: Member Report of Malaysia", retrieved on retrieved on 26-5-10.

[9] Bruni, A. Gherardi, S, \& Poggio, B. (2004). EntrepreneurMentality, Gender and the Study of Women Entrepreneurs Journal of Organizational Change Management. Vol. 17 No. 3. (pp. 256-268). Emerald Group Publishing Limited

[10] Central Bank of Kenya (2003). African Development Indicators: 1987, 2000 and 2002. Central Bank of Kenya, monthly economic review July 2003.

[11] Hadiya M. (1998). Sharing Experiences: Success Stories of Women Entrepreneurs. Addis Ababa. Unpublished.

[12] Helms, M. (1997). Women and Entrepreneurship. The Appealing Alternative. Business Perspectives. 10(1)16-19.

[13] Kothari, C. R. (2003). Research Methodology: Methods and Techniques. Second Edition. New Age International (P) Ltd.

[14] K-REP. (1999). Savings Needs of K-REP Client: Case Studies Vol. 1, February. Marris, P. and Somerset A. (1971). African Businessmen: A study of Entrepreneurship and Development in Kenya. London: Routledge and Kagen Paul Ltd.

[15] McCormick, D. (1988). Funds and Formality. Very Small Manufacturers in Nairobi. In Political Economy of Kenya, edited by Schartzerberg, M. G. New York: Praeger Publishers.

[16] Mugenda, O. M., and Mugenda A. G. (1999). Research Methods: Quantitative and Qualitative Approaches. Nairobi: Acts Press.

[17] Musinga, J. M. (1994) The Impact of Small Loans on Employment in Small and Micro-Enterprises in Kenya. K-Rep Research paper No. 19, Nairobi Kenya. 